\title{
El niño como sujeto de derechos y la escritura literaria infantil ${ }^{1}$
}

\section{The Child as a Subject of Rights and Children's Literary Writing}

\author{
Alexander Ruiz Silva ${ }^{2}$ \\ Manuel Prada Londoño ${ }^{3}$
}

\section{Resumen}

Este texto se centra de manera especial en la imaginación de los niños y su expresión escritural. El eje central de las historias de alumnos de cuarto grado de básica primaria (ocho años, en su gran mayoría) de la escuela pública en Bogotá en la que se llevó a cabo el proyecto de investigación-acción sobre el niño como sujeto de derechos giró justamente en torno a los derechos vulnerados, mancillados, defendidos y, en algunos casos, restaurados a la infancia. Los distintos apartados del escrito dan cuenta de elementos relacionados con el origen, contexto, fundamentos y proceso de esta experiencia pedagógica-investigativa, así como de sus principales resultados, que no podrían ser otros que la misma producción escritural de los niños participantes.

Palabras clave

Niños, sujeto de derechos, escritura, texto literario.

\section{Abstract}

This paper focuses especially on the imagination of children and their written expression. An action-research project about children as subjects of rights was carried out, where the centerpiece were the stories written by fourth graders (mostly 8 years old) from a public elementary school in Bogotá. The stories talked around children's violated, defiled, screened, and, in some cases, restored rights. The different sections of the paper refer to aspects concerning the origin, context, basis, and development of this pedagogical-research experience, as well as the main findings, which could not be other than the same literary production of the children who participated in the experience.

Keywords

Children, subject of rights, writing; literacy text.

Artículo recibido el 27 de octubre de 2014 - aprobado el 17 de noviembre de 2014

1 Este artículo es parte de la producción escritural del proyecto de investigación El niño como sujeto de derechos. Formacióninvestigación de una cultura de los derechos humanos en la escuela primaria, auspiciado por el Centro de Investigaciones de la Universidad Pedagógica Nacional CIUP (DED-335-12-1), realizado con maestras y alumnos de escuela primaria del Instituto Pedagógico Nacional (Bogotá).

2 Profesor titular de la Universidad Pedagógica Nacional. Miembro del grupo de investigación Moralia.

3 Estudiante del Doctorado en Filosofía Contemporánea y Estudios Clásicos de la Universidad de Barcelona. Miembro del grupo de investigación Moralia. 


\section{Entrando al laberinto}

La idea de que el niño se piense a sí mismo como sujeto de derecho mediante la escritura de textos literarios puede ser sumamente enriquecedora en varios sentidos. En primer lugar, el hecho mismo de que los niños se asuman como autores, como creadores de historias, le otorga lugar a su imaginación, protagonismo a sus ideas, resonancia a su palabra. Se trata del reconocimiento del mundo vital de niños y niñas al que vale la pena darle un lugar en las clases, en relación con los temas que el dispositivo escolar ha considerado objeto de enseñanza. Dicho reconocimiento permite que tengan lugar las preguntas, las dudas y la inconformidad de los niños con algunos asuntos que les afectan, les rodean y les suscitan inquietudes y retos. El trabajo de producción escritural suele enlazar algunas de estas cuestiones permitiéndoles a los niños expresar una parte importante de su universo simbólico, que entra en diálogo con otras formas de expresión y de comprensión de los problemas que van emergiendo en el tejido de palabras y silencios que configura la experiencia escolar.

En segundo lugar, la persuasión hacia la elaboración de historias a temprana edad habilita una valoración positiva del oficio de escribir y una consideración especial de que a través de las letras los seres humanos pueden imaginar, idear, interpretar, crear, expresar y soñar mundos posibles. Por ello, la escritura sobre justicias e injusticias, dichas y desdichas, buen trato y mal trato, así como sobre la realización o negación de la dignidad humana en personajes y situaciones creados por los niños es una gran oportunidad de exploración de sus ideales de vida buena, de las normas familiares, sociales, morales y políticas que se ven abocados a aprender, a rechazar o a significar en su vida cotidiana y de sus propias convicciones fraguadas al tenor de los escenarios conflictivos y las tensiones sociales que enfrentan a diario, de las que son testigos o simples observadores, aquellas que han vivido o que imaginan pueden estar viviendo otras personas. En esa articulación, presente en la escritura literaria, entre los ideales de vida buena, el ámbito normativo y las convicciones que alumbran el sentido de una toma de posición, los niños pueden comprender que la palabra tiene una fuerza performativa en la descripción de situaciones, la definición de conflictos y la proposición de mundos posibles.

La apuesta por la expresión literaria pone de presente el enorme valor de la palabra, de la palabra dicha, pero también de la que no hay necesidad de pronunciar o de escribir porque el ambiente narrativo no lo requiere, de la palabra que espera ser convocada para hacerse pública, para expresar lo que su autor desea. En este ejercicio de expresión literaria el valor de la palabra escrita enlaza el de la palabra leída; así, se va dibujando el arco que enlaza al escritor con el lector, arco que indica que todo acto escritural compromete éticamente un acto lector, un esfuerzo por comprender y reconocer el significado de la palabra del otro. Así, cuando se es sujeto de lenguaje se es sujeto de comunicación y, de esta manera, sujeto moral, sujeto de derecho, participante activo del universo lingüístico-simbólico que a todos nos configura.

La apuesta por la escritura literaria es, igualmente, una manera decidida de promover la creación de vínculos de significado con lectores potenciales y no solo con lectores actuales y concretos; es querer hacer presencia en la vida de quienes no están presentes. En ello reside la promesa de toda creación, en el espíritu de apertura hacia nuevos y futuros lectores, hacia nuevas y futuras interpretaciones y apreciaciones sobre lo creado. La contracara de esta apertura suscitada por la escritura literaria es la lectura literaria, que hace del autor comprometido y recursivo un lector curioso, abierto, agradecido, que encuentra en los textos una forma de hacerse sujeto moral mediante la identificación con personajes, situaciones, decisiones y acciones capaces de interrogar sus propios ideales de vida, de cuestionar las normas que asume y de acrisolar las convicciones que se juegan en situaciones de conflicto.

La experiencia de creación literaria -con alumnos de cuarto grado- en torno al niño como sujeto de derecho, que expondremos a continuación, se enmarcó en estos planteamientos. Veamos cómo resultó esta aventura. 


\section{En medio del bosque de palabras ${ }^{4}$}

A escribir también se aprende, como se aprende a caminar, a hablar, a callar, a abrazar, a apreciar las cosas de la vida. Por supuesto, cada uno de estos aprendizajes es distinto uno del otro, cada uno plantea exigencias específicas y algunos de ellos nunca se dominan del todo. Es común oír decir que incluso a los más grandes escritores les cuesta mucho escribir todo lo que quisieran y de la forma en que quisieran hacerlo o que se encuentran permanentemente exigidos en la búsqueda del tono, del estilo, de las palabras precisas para sus historias y personajes. Así, si la escritura es algo tan complejo y desafiante para quienes la tienen como oficio, no puede serlo menos para quienes la usan ocasionalmente como forma de expresión, comunicación o cumplimiento de tareas. No obstante, todos pueden acceder, con mayor o menor esfuerzo, a sus posibilidades expresivas, intelectuales, emocionales y estéticas. Esta es, justamente, una de las apuestas del proceso pedagógico orientado a que los chicos escriban textos literarios en la escuela primaria.

Partimos de la consideración de que el desarrollo de habilidades básicas de escritura en la escuela (codificación y decodificación de signos, transcripción y reproducción de información, composición gramatical, manejo de signos de puntuación, ortografía, caligrafía, digitalización, entre otros) puede ser enriquecido mediante la invitación a la escritura de textos de ficción; al mismo tiempo, la mejora en los procesos mencionados puede favorecer la aventura de la creación literaria. No se trata de subordinar una cosa a la otra; por el contrario, se trata de propiciar el encuentro, el diálogo entre el lenguaje convencional escrito y la ilimitada capacidad imaginativa de los seres humanos, en este caso en particular, de los niños. En esta misma dirección, podemos

4 Buena parte de la estructura de los acápites que siguen se apoya en el trabajo pedagógico que usualmente desarrolla la profesora Dalila Castillo con estudiantes de cuarto grado del Instituto Pedagógico Nacional (Bogotá) en la clase de lengua castellana, apoyada a su vez en Gianni Rodari. La profesora y los niños acogieron con generosidad la propuesta de leer y escribir, en esta ocasión, en torno a la idea del niño como sujeto de derecho. Presentamos aquí, de manera concisa, el resultado de este encuentro de intereses diversos y a la vez complementarios. decir con Rodari que este ejercicio es una apuesta por la creatividad infantil. Para este autor italiano, la creatividad es sinónimo de divergencia, crítica, interrogación, rechazo a lo codificado, inconformismo propositivo y juicio autónomo e independiente (1998, p. 157). Todas estas propiedades de la creatividad permiten apostar por la virtud liberadora que puede tener la palabra. "Todos los usos de la palabra para todos", me parece -prosigue Rodariun lema bueno y con agradable sonido democrático. No para que todos sean artistas, sino para que nadie sea esclavo" (p. 12).

Ahora bien, ¿ cómo invitar al niño a la escritura de ficción? ¿Cómo estimular su capacidad creativa en el desarrollo de historias sobre temas tan complejos como la idea del niño como sujeto de derechos? No hay y no podría haber respuestas definitivas a este tipo de preguntas, pero, por supuesto, sí es posible proponer algunas opciones tentativas. Veamos.

\section{Mi reino por una estrategia}

Entre las diversas estrategias, métodos y procedimientos para propiciar la escritura ficcional en niños pequeños que les permitan mejorar sus habilidades lingüísticas, liberar su imaginación, expresarse de modo estructurado y combinar distintas formas de narración, se optó aquí por las orientaciones pedagógico-literarias de Gianni Rodari presentes en su texto Gramática de la fantasía.

Este autor propone variadas y sugestivas estrategias para que el niño pueda enfrentar el papel en blanco, entre las que se cuentan:

- El hombrecito de vidrio, que consiste en la elección de un personaje, un hombre, una mujer, una niña o un niño hecho de un material específico, que para el caso es vidrio, pero que los niños pueden cambiar por arcilla, metal, chicle, plástico, papel o lo que elijan y que, en cualquier caso, ha de enfrentar, en su trasegar, circunstancias inciertas o conflictivas, a partir tanto de su propia naturaleza material como del tipo de relaciones que puede establecer con los demás personajes de la historia. De este modo, un niño de cera difícilmente 
puede salir a jugar al recreo de la escuela en una mañana soleada, si quiere evitar el riesgo de derretirse, así que el autor o autora de esta eventual historia habrá de hacerse cargo del peso de las dificultades y del desenlace de su propia creación. Rodari (1998, p.86) subraya de esta estrategia la articulación entre dos lógicas que juegan pendularmente en la creación literaria: una, referida al análisis de los materiales y otra, al análisis fantástico. El primero, añadimos nosotros, les exige recrear los conocimientos adquiridos sobre el material escogido, conocimientos que involucran vivencias personales, información obtenida en su cotidianidad, en el aula, la biblioteca, los medios de comunicación, entre otros escenarios; el segundo les permite extrapolar el conocimiento de lo real para remodelarlo con la fuerza de la imaginación. En el cruce entre ambos emerge metafóricamente el conflicto que hace evidente, entre muchas otras posibilidades, lo que significa vivir en un mundo siendo de determinada manera, etiquetado en función de capacidades o incapacidades atribuidas por otros o entablando relaciones con otros que tienen propiedades anheladas y que, a su vez, padecen avatares similares.

- El binomio fantástico les permite a los niños establecer relaciones entre un par de objetos que ellos mismos deben elegir. Rodari resalta la necesidad de distancia, extrañeza entre las dos palabras, "para que la imaginación se vea obligada a ponerse en marcha para establecer entre ellas el parentesco, para construir un conjunto (fantástico) en el que puedan convivir los dos elementos extraños" (p. 22). La disonancia inicial que puede suscitar el binomio "perroarmario" - este es el ejemplo que trae a colación Rodari- se vuelve un reto para la imaginación: ya no se está hablando de un mamífero de cuatro patas, ni de un mueble inerte de madera u otro material, sino que "perro" y "armario" se cargan de posibilidades de significado en las relaciones que podamos establecer entre ambas. La palabra ya no es unívoca, la relación entre cosas del mundo puede romper los estancos de lo establecido, la historia que surja de la explosión de sentidos será rica en personajes, circunstancias y sorpresas.

Rodari continúa con el ejemplo de "armario" y "perro" y establece tres posibilidades: "un perro pasa por la calle con un armario a cuestas", y habrá que explicar por qué; contar, por ejemplo, que la carga es como una especie de caparazón; "el armario del perro", que podría suscitar la escena de una casa tan lujosa que el perro tiene su propio armario para guardar huesos, juguetes, collares... y "el perro en el armario", en la que un hombre abre la puerta de su armario y encuentra allí un perro. En este caso, la historia tiene que dar cuenta de la situación, explicar esta aparición -quizás se trata de una invasión de perros que llenan todos los armarios de la casa, sigue Rodari (p. 23). Como se ve, se trata de que alrededor de dos palabras se genere un mundo y este se presente de manera verosímil.

- La tercera de las propuestas de Rodari se articula en torno a la fórmula: ¿Qué ocurriría si...? (pp. 29-31). La técnica, llamada también "de las hipótesis fantásticas", consiste en la elección, al azar, de un sujeto y un predicado (un verbo para comenzar) cuya unión forma una pregunta. Si el sujeto es "ciudad" y el predicado es "trabajar", se pueden formular preguntas como: ¿qué pasaría si en esta ciudad nadie tuviera que trabajar? Luego, sugiere el autor italiano, se imaginan las reacciones de las personas, los incidentes a que pudiera dar lugar esta situación hipotética, las discusiones que se suscitarían. También se puede escoger un personaje para que en torno a él gire la historia y luego comenzar a darle la estructura al cuento mediante la creación de los eventuales comienzos de las historias, con desarrollos y finales inesperados. Rodari llama la atención sobre el hecho de que la pregunta que inicialmente parece surgir de un absurdo se convierte en una entrada distinta a la realidad vivida, una forma de ver a la distancia aquello que se ha hecho próximo como posibilidad. 
Por supuesto, estas opciones operan a la manera de pautas que facilitan el inicio del proceso escritural y en ningún caso son una camisa de fuerza dirigida, acaso, a la homogenización de sus historias. Por tanto, la construcción de los personajes, el espacio y el tiempo en que transcurren los acontecimientos, la narración de cada una de las situaciones creadas: aventura, infortunio, prodigio, ironía, asombro o broma, aunque pertenecen al ámbito de elección de los niños, pueden ser interrogados o comentados por la maestra en función de la coherencia y solidez de los cuentos escritos por los niños.

Una vez se expone cada una de las estrategias mencionadas, los chicos eligen aquella con la que más cómodos se sienten o la que, en principio, mayormente puede facilitar su labor escritural. Esto se complementa con la presentación de pautas básicas sobre la estructura de un relato, para lo cual se leen en clase algunos ejemplos de cuentos infantiles que permiten identificar con relativa facilidad el inicio, nudo y desenlace de un cuento. De igual modo, se hace en el aula una exposición de distintos tipo de narraciones (fantástica, de aventuras, otras) para que los chicos puedan encuadrar su escrito en alguna de ellas o, si es el caso, combinar las distintas modalidades aprendidas.

\section{El maravilloso aroma del borrador}

La elaboración del primer borrador del cuento está antecedida de una actividad en la que cada niño presenta, por escrito, una especie de lluvia de ideas, esto es, asuntos o situaciones sobre los que quiere elaborar su escrito y la estrategia de la cual desea valerse. Esta es una gran oportunidad para que la maestra empiece a orientar el proceso creativo animando a los niños a desarrollar las ideas más potentes, haciendo precisiones sobre las características básicas de la estrategia elegida e insistiendo en la importancia de la estructura, cohesión y coherencia del escrito.

De modo complementario, se les enseña a los niños a usar las convenciones que permitan fácilmente distinguir en su escrito la descripción de un lugar o de una situación o de un diálogo entre sus personajes. En esta dirección se escriben en la pizarra algunos ejemplos sobre uso adecuado de los signos de puntuación, especialmente el punto seguido, el punto aparte, los dos puntos y el guión. A medida que se trabaja en torno a estos elementos, se destaca que no todos los finales tienen que ser iguales, que así como hay finales felices, los hay también tristes e incluso inciertos; que si bien algunas historias no se parecen en nada a la realidad vivida, otras se pueden parecer mucho y reflejarla total o parcialmente. Con estos elementos en la alforja, los niños emprenden la aventura de escribir el primer borrador. Esta escritura puede comenzar en la clase y continuar en casa, según se logre establecer un ambiente adecuado para ello.

Es muy importante que los niños entiendan que, si bien todo proceso creativo suele tener momentos de lucidez espontánea, solo se puede llegar a buen puerto con esfuerzo, dedicación y perseverancia. Por ello es necesario enseñarles el valor de la revisión y la corrección, y que la construcción de toda obra es a la vez un proceso de aprendizaje. Casi siempre hay asperezas, incorrecciones, yerros que solo se pueden superar a medida que se hace conciencia de ellos y se tiene la suficiente paciencia para intentarlo de nuevo. Solo así se puede entender el valor del esfuerzo y de paso desmitificar la idea de que la creación es el privilegio exclusivo de mentes elegidas. No de manera desprevenida Picasso afirmaba: "La inspiración existe, pero tiene que encontrarte trabajando".

La revisión del primer borrador permite corregir problemas en la construcción gramatical y en otros aspectos formales de la escritura; sugerir precisión en la composición de las historias, coherencia y consistencia en la estrategia expositiva -según se requiera-; resaltar logros y potencialidades en el estilo narrativo, en las situaciones descritas y en la configuración de los personajes. Como es sabido, la manera como se enseña es tan importante como lo que se enseña, por lo que no es lo mismo recibir las anotaciones y correcciones en un tono tajante y rudo que en uno sugerente y amable.

Una vez los cuentos han pasado por este primer tamiz, se emprende la escritura del segundo borrador. En la revisión de cada versión es necesario man- 
tener los criterios de exigencia en la escritura y resaltar los aspectos valiosos de cada historia. El número de borradores dependerá del tiempo disponible o proyectado para la realización de todo el ejercicio, de la calidad de los textos, de la motivación de los niños y, en general, de la dinámica de la clase. Bien vale la pena invitar a la familia a la lectura de los borradores con miras a que los chicos obtengan aliento y reconocimiento en su proceso creativo y sugerencias de corrección de algunos de los aspectos formales de sus escritos.

La escritura de la versión final, unos meses después de iniciada la experiencia, es un momento especial, pues representa el cierre de una actividad que convirtió a los niños en autores, en los dueños del destino de sus personajes y en los responsables de las sensaciones, emociones, razones, certezas, dudas, desafíos que plantea su propia creación. Por ello, si se ha convenido la entrega de un texto manuscrito, vale la pena resaltar la importancia de la presentación del trabajo y de una juiciosa caligrafía, dejándolos en libertad de utilizar hojas de colores o de acompañar sus cuentos con ilustraciones, dibujos $\mathrm{u}$ otros detalles de su preferencia.

\section{Las hojas de laurel}

El paso de las hojas de colores a las hojas de laurel nos permite simbolizar una parte importante de este proceso de aprendizaje y de creación escritural. Es necesario antes dar un pequeño rodeo.

Originario de las costas del Mediterráneo, el laurus nobilis llega a medir hasta quince metros de altura. Se trata de un bello y aromático árbol usualmente usado como condimento en la cocina, aunque también se lo considera de enorme utilidad en la medicina homeopática, atribuyéndosele propiedades antibacterianas favorables al tratamiento de distintas dolencias corporales (cansancio, artritis, resfriados, entre otros).

Su importancia simbólica quizás sea aún mayor. Ovidio, en su célebre libro La metamorfosis, recrea el origen mítico de la corona de laurel, símbolo de poder y nobleza. En el centro del mito, dos dioses orgullosos se enfrentan en una dura contienda: se trata de quién puede disparar mejor y más lejos una flecha. Ante la insolencia y presunción de Apolo por su ventaja en la competencia y por su triunfo inesperado, la diosa Eros urde un plan: fabrica dos flechas mágicas de materiales distintos y efectos contrarios, la flecha de oro tiene el poder de producir un amor inmediato e infinito a quien sea tocado por ella, mientras que la de plomo produce en su víctima un irreversible rechazo amoroso. Justo cuando Apolo ve a Dafne es herido de amor, casi al tiempo que esta es tocada por la segunda flecha. Se trata de la historia de un desencuentro, de un cortejo no correspondido, de un amor que solo obtiene a cambio desamor y de la intensa y dolorosa persecución a la que Apolo somete a Dafne. Cuando la bella mortal ya no puede escapar del dios enamorado, se hace inevitable la metamorfosis; así, sus pies se hunden en la tierra, su cuerpo se transforma en tallo, en corteza, en ramas, y sus cabellos, en hermosas hojas. Con gran desasosiego, Apolo se abraza al árbol y con lágrimas en sus ojos dice: "puesto que no puedes ser mi mujer, serás mi árbol predilecto y tus hojas, siempre verdes, coronarán las cabezas de las gentes en señal de victoria".

Haciendo honor a esta historia, primero en la antigua Grecia y un poco más tarde en Roma, en ceremonias especiales se posará sobre la cabeza de poetas, guerreros y atletas una corona de laurel -lauréola-. En adelante, se mantendrá la buena costumbre de laurear a quienes alcancen reconocimientos, notoriedad en un campo del saber y de las artes.

El rodeo por el significado mítico del árbol, las hojas y la corona de laurel nos permite llegar al momento de elegir entre todos los cuentos, aquellos que más méritos reúnen, aquellos que merecen ser laureados. Pero ¿a quién encomendarle la tarea de esta elección? Como debería suceder con la llamada literatura infantil o con la escritura dirigida a los niños, no podría haber un jurado más calificado que sus mismos destinatarios. Así, en una pequeña jornada reservada a este propósito, los niños leen sus cuentos y eligen los mejores, esto es, las historias que más fascinación les produjeron, las que más convocaron su atención, despertaron su curiosidad y satisficieron sus expectativas. 


\section{Los unicornios de esta historia}

$\mathrm{Al}$ igual que sucede con otros animales fantásticos como basiliscos, grifos y dragones, los principales atributos de los unicornios yacen en la imaginación humana. Entre mitos y leyendas se ha ido decantando la forma de un hermoso caballo blanco, con patas, barba y cola de otros animales y un largo y poderoso cuerno en la frente. Convengamos, por ahora, en esa imagen arquetípica y centrémonos en la magia que la palabra ha ido creando en torno suyo a través del tiempo.

En la Edad Media, fascinados por las historias sobre la gracia, belleza y escasez de los unicornios y los poderes atribuidos a su cuerno en espiral, viejos reyes, príncipes herederos, señores feudales y jerarcas de la Iglesia, obsesionados con una longeva existencia y con la obtención de un remedio efectivo contra el veneno de potenciales traidores, encomendaron a fieles militares y mercaderes viajar grandes distancias -a la India, especialmente- en busca de los afamados animales. Por supuesto, el propósito era cazarlos y cortarles el cuerno, con el que luego de triturado se pudiera rociar los alimentos de la perennidad $^{5}$.

Es de suponer que en dicha época las grandes cantidades de dinero destinadas a financiar estas expediciones hicieran progresar ostensiblemente la industria del fraude, aunque, de paso, las mismas aventuras contribuyeron a que la astucia se hermanara con la imaginación. De esta relación proceden las historias sobre la gran fuerza, velocidad y fiereza del unicornio y la probada dificultad para cazarlo. Esta misión solo podía facilitarse mediante la parti-

5 Un fragmento de la novela El unicornio, de Manuel Mújica Laínez (1979, p. 38), nos ayuda a ilustrar el poder curativo atribuido al cuerno del unicornio. Allí escribe del cuerno que es "talismán precioso, que solía esconder en su base un carbúnculo curativo de enfermedades, poseía la virtud de preservar contra los sortilegios $y$ de ennegrecerse al entrar en contacto con cualquier materia venenosa. Por eso los árabes incrustaban un trozo de unicornio -cuando lograban, a cambio de bolsas de oro, conseguirlo- en los mangos de los cuchillos que empleaban en sus festines. En este caso, si la comida era tóxica, un leve sudor informante cubría la hoja de metal. Por eso tuvo uno Lorenzo el Magnífico. Y es fama que si el monoceronte lo hundía, al beber, en el agua de un río, el líquido hervía, formando una nívea espuma que hacía huir a las alimañas mortíferas; entonces los demás animales aprovechaban para beber por turno y el unicornio benéfico quedaba aparte". cipación, en la cacería, de una joven y virginal doncella. Ella debía caminar serena por el bosque hasta lograr atraer y apaciguar a la esquiva bestia. Así, ante la caricia de otro ser bello e inocente, el unicornio se hacía más vulnerable a la presencia de las sogas, las trampas y las armas.

Decíamos antes que de este bosque encantado de palabras y sensaciones surgen los unicornios de esta historia y no es para menos, pues los cuentos escritos por los niños están precedidos de esfuerzo y llenos de vitalidad y magia. Pero acaso esta figura de los poderes curativos del cuerno nos sirva para pensar en la fuerza terapéutica de la palabra hecha vida, diálogo, personajes y acciones en los cuentos escritos por los niños, así como en el milagro de reconocimiento que supone destacar y celebrar el esfuerzo por todos realizado, los múltiples aprendizajes que se pueden extraer del ejercicio, los nuevos desafíos que plantea la lectura y la escritura. Es como si el cuerno de la palabra mágica que circula en la escuela se hundiera en las aguas a veces turbias de mutismo, de invisibilidad, de escrituras y lecturas estériles y permitiera reconocer, valorar y exaltar a los autores de las historias, su perspectiva de mundo, su forma de cuestionar aquello que los afecta y aquello con lo que sueñan ${ }^{6}$.

A continuación, presentamos solo algunos de los cuentos que los mismos niños de cuarto grado de educación básica que participaron de esta experiencia destacaron y que nos sirven para hacer un balance provisional de nuestra estrategia:

\section{El niño de palo}

\section{Juan Esteban Gómez}

Un día el niño de palo iba al bus y lo secuestraron. Entonces llamaron a la mamá:

- Han secuestrado a su hijo.

6 Puede reforzar este reconocimiento una pequeña compilación que habrá de considerar algunos cuentos por cada uno de los grupos participantes (clase, aula, comisión) con los que se lleva a cabo esta actividad. Una forma de darle mayor relieve al trabajo realizado es publicar en físico o en formato virtual (en la web de la institución o en un blog diseñado para este propósito, entre otras opciones) los cuentos laureados 0 , si es posible, la totalidad de los trabajos de los chicos, según los recursos de los que dispone cada institución. 
La mamá quedó muy sorprendida y se puso a llorar. Todos los vecinos vinieron y le preguntaron:

- ¿Qué pasa?

Y ella les dijo:

-Secuestraron a mi hijo.

Y dijeron:

-Llama a la policía.

Y llamó y reportó el caso y al colgar tenía un mensaje que decía:

- Tenemos a su hijo, denos cinco millones y le daremos a su hijo, ¡llámenos, sí, sí!

El niño palo hábilmente se escapó mientras ellos hablaban por teléfono. Él directamente se fue a la policía y no lo quisieron recibir por ser niño y él empezó a llorar porque todos lo miraban mal, pero un policía fue el único que se dio cuenta de lo que le estaba pasando al niño palo y se le acercó y le dijo:

- Tranquilo, yo te entiendo, dame los datos de tu mamá, yo la llamo y todo se solucionará.

El niño palo se puso feliz de saber que estaría de vuelta con su mamá. Todos entendieron que no hay que mirar solo lo exterior, sino que también los sentimientos de las personas y el interior de cada una y todos se disculparon con él y aprendieron la lección y quedaron felices para siempre.

\section{Rudo, Antón y el aliento mágico}

\section{María Juliana Rincón}

Hace algún tiempo conocí a un pequeño niño llamado Rudo, con actitud de tener pocos amigos y con una prepotencia que hacía pensar que nada ni nadie eran de su interés. Pero sucedió que había alguien totalmente opuesto a este. Era un niño tan especial que ni ustedes, ni Rudo siquiera, podrían imaginar. Era Antón, su sola presencia hacía inquietar. Aparte de todo, Antón tenía un poder grande, su aliento congelaba como el hielo, pero con una virtud: que solo congelaba los sentimientos equivocados de las personas como Rudo, que pensaba que siendo grosero y desobediente conseguiría con sus malas acciones el respeto o temor de muchos.
Entre otras cosas, existía un libro llamado Los derechos de los niños; este libro era desconocido, pues el papá de Rudo lo escondió bien para que nadie se revelara contra él o sus ideas, lo que quería era someterlos sin derecho a elegir.

Este maravilloso libro expresaba cosas como el derecho a la educación, el derecho a un nombre, a tener hogar, etc., pero el papá de Rudo haría lo que fuera para que este libro no cayera en manos de los niños. Sin embargo, su propio hijo Rudo se encargó de que este secreto saliera a la luz, pues Antón se había encargado de cambiar a Rudo y con su poder lo ayudó a ser un niño con buenas actitudes, responsable y un gran ser humano. Y es así como Rudo se encargó de que todos los niños fueran muy felices, conociendo sus derechos y deberes que los haría libres e independientes y muy juiciosos, y cada niño pudo aprender de los derechos y deberes.

\section{Qué pasaría si los ángeles pisaran la Tierra}

\section{César Andrés Cantor}

Había una vez un mundo donde los niños no eran escuchados ni por sus padres, ni por sus profesores, porque a través del tiempo los pequeños se fueron convirtiendo en estorbo para los mayores. Ya ninguna familia quería tener hijos, porque no había tiempo para ellos. El trabajo, el dinero, los viajes y las reuniones sociales no daban tiempo para la incómoda labor de la crianza.

Los pocos niños que quedaban vivían la mayor parte del tiempo al cuidado de personas extrañas a quienes los padres les pagaban dinero para cuidar a sus fastidiosos hijos.

Cuando algún niño tenía la osadía de hablarle a algún adulto, este, sin importarle nada, le respondía con un grito o un golpe. Un día, un hombre con un extraño resplandor llegó a este frío mundo y empezó a tratar con amor a los niños. Los adultos miraban con rabia a ese hombre, empezaron a dejar a sus hijos bajo llave, no los dejaban hablar con ese hombre. Este hombre les habló a los adultos y les recordó que estaban envejeciendo y los niños creciendo. 
Sintieron dolor y vergüenza, buscaron acercarse a los niños, pero estaban mal por el maltrato, entonces debieron hacer un gran esfuerzo para ganarse el amor de sus hijos.

Con el tiempo los niños perdonaron. Aquel hombre desapareció.

\section{El reino mágico de Igualia}

\section{Juan Pablo Gil Pardo}

En la provincia de Bella las Once frente al particular espejo recién traído del territorio de los artesanos prodigiosos por Xabia, su amada madre, Tizziano practicaba el discurso que dará frente a la comunidad para defender a las mariposas de alas doradas, que están en peligro de extinción.

De pronto, una luz muy fuerte que emanaba del espejo lo atrajo hasta golpearse la cabeza. Cuando despertó, sobre él estaban las miradas de los niños de color púrpura y de color naranja, de la cabeza a los pies, también su ropa.

Pensó que era un sueño, cerró los ojos y antes de volver a abrirlos lo siguiente que escuchó fue:

-Infectado, no tiene color, es diferente.

Tizziano alarmado se levantó y dijo:

-Soy un niño normal, ustedes son... naranjas, púrpuras, todos igualitos, ¡no! ¿Dónde estoy?

Siguió un gran escándalo, todos gritaban:

-Un diferente, un infectado.

Allí todo era extraño, todo se repetía muchas veces, los habitantes eran de color naranja, púrpura, igual las casas, los árboles. Tizziano había llegado al reino de Igualia.

-Rápido, llévenlo ante los principales, rompió el orden del reino.

Lo llevaron a empujones, hasta el patio del palacio. Un guardia alarmado preguntó:

- ¿Qué es eso?

-Un infectado, diferente.

De inmediato los principales, molestos por la gritería, salieron a poner orden.

- ¿Qué es lo que pasa?
Tizziano aliviado se dirigió a los cuatro adultos, a quienes llamaban principales:

- Soy un niño, no puedo decir más.

La gente gritó:

- ¡Diferente, diferente, infectado, extraño, que lo castiguen! ¡Diferente, infectado, extraño, que lo castiguen!

Era un coro que asustaba.

-Debe ser púrpura.

-No, que sea naranja.

Pasaron unas horas y por fin los principales, como los llamaban, porque ninguno tenía nombre, dijeron: -El diferente es condenado a la cueva del olvido, por ser diferente, por tener nombre, por hablar sin que nadie se lo pida, ¡desteñido!

- Será entregado a la Kuruka y trabajará para ella. Debe pagar por la ofensa al reino de Igualia.

Tizziano no pudo aguantarse y pidió la palabra:

- No pueden quitarme mi libertad, soy un niño, tengo una familia. Los niños no trabajamos. Yo estudio y además defiendo las mariposas de alas doradas. Me llamo Tizziano, mi familia me ama ¡respétenme mis derechos! — gritó desesperado al ver que nadie le ponía atención.

Al contrario, le gritaron:

-Está loco, perdió la cabeza, que lo castiguen, a la cueva del olvido.

En una carreta, atado, amordazado, era llevado Tizziano, que lloraba amargamente. Anochecía y aterrado se preguntaba:

— ¿En qué lugar estoy? ¿Por qué me pasó esto?

Parecía una pesadilla y quería despertar. Pero una voz ronca de una mujer lo hizo temblar.

-Aquí está el detenido, el diferente, el insolente. Intentas acabar con mi reino. No sabes que aquí mando yo y todos obedecen. Nada debe cambiar. Pagarás como mi sirviente.

Tizziano, amordazado, gemía. La Kuruka molesta lo liberó de la mordaza. El niño tomó aire y con valor le dijo:

-Yo no soy de aquí, no voy a obedecer, tengo derechos, me llamo Tizziano, voy al colegio y me gusta jugar y defiendo a las mariposas de alas doradas. 
La Kuruka cambió su expresión de amenaza a preocupación. Ordenó a los hombres naranja que lo llevaran dentro de la cueva y cuando estuvieron a solas lo miró con atención y le preguntó:

- ¿Niño, de dónde vienes?

-Del Reino de Bella las Once.

La Kuruka enmudeció. Pasaron varias horas y Tizziano se moría de hambre y ella se dio cuenta. Con un pase mágico le soltó las manos y le pasó un jarro con algo de beber, en el segundo sorbo se sintió mareado, su piel comenzó a colorearse purpura. Asustado comenzó a llamar a su mamá y lloró tanto que se quedó dormido.

En sueños regresó al bosque de las mariposas de alas doradas, en su reino de Bella las Once. El sol reflejaba luces de colores en las alas doradas de las mariposas que revoloteaban lanzando lindos destellos. Estaba tan contento y maravillado que fue sorprendido por el toque del hada de las mariposas, y emocionado dijo:

- ¡Sí existes! Hada, ¿vienes a ayudarme a salvar a mis mariposas?

- No exactamente. La verdad es que estoy en tu sueño y debes despertar después de que te diga cómo liberar a Galia.

—¿Cuál Galia?

-El reino que has conocido como Igualia.

-No, no quiero volver, me asusta.

-Tú eres el defensor de las mariposas, eres un niño especial y valiente. No temas, déjame contarte: la Kuruka fue una reina muy bella, rica, poderosa. Cada vez quería más riquezas y reconocimiento, todos sus súbditos debían adorarla. El poder la hizo egoísta, tirana. Una noche, mientras se realizaba un baile en honor a un rey de un reino lejano, que la pretendía y del cual ella se había enamorado, vino una tormenta de lluvia y granizo, truenos, rayos cayeron del cielo. El palacio se destruyó y mató a su amado. Ella no lo soportó, se llenó de odio, de rabia. Se internó en la cueva del olvido donde vivía una bruja. Por un tiempo no se supo más de ella.

Pero un día en el campo apareció un camino de bolas naranja y purpura, parecían manzanas, tenían un aroma exquisito, tanto que cada habitante de Galia no pudo evitar morderlas hasta terminarlas $\mathrm{y}$ uno a uno fueron cayendo hechizados. Cuando se durmieron, ella robó su libertad, sus sueños, memorias y recuerdos.

Cuando despertaron no poseían nada y eran de los dos colores que has visto, sin nombre, sin voluntad. Obedecían ciegamente a la Kuruka. Tú debes salvarlos; para ello, debes rociar de polvo de las alas de las mariposas doradas a la Kuruka. Muerde los lazos que te atan -son de caramelo- y pónselos a ella. Luego busca un gran libro dorado de Galia y corre hacia fuera, no regreses por nada. ¡Despierta ya!

Tizziano, incrédulo, abrió los ojos y recordó morder las ataduras. Cuando estuvo libre tomó la bolsa y pensó: "el hada sí estuvo aquí". Temblando se dirigió hacia donde estaba la Kuruka y la encontró dormida. Sin demora abrió la bolsa y comenzó a echarle el polvo a la Kuruka; ella despertó, pero era tarde. El polvo de las mariposas de alas doradas hizo su efecto y ella quedó como estatua. Tizziano buscó el libro dorado, no lo encontraba, al fin en un baúl brilló, lo agarró y comenzó a correr, pues la cueva se cerraba.

Abrió el libro dorado con mucha curiosidad:

-Galia, reino de la alegría: derechos y deberes.

Caminó sin saber a dónde llegaría. Había partido al amanecer; mientras caminaba y descubría la historia de Galia, el sol bajaba hasta tocar la sabana. Reconoció el palacio y sintió angustia, pero el cielo se llenó de luces de colores. Los niños y niñas, las mujeres y hombres lucían como él, distintos, las casas, los árboles, todo recobró su color natural.

Nadie lo señalaba ni le gritaban, todos le sonreían, se veían felices. Cuando estuvo frente al castillo levantó el libro dorado y los anteriores adultos, ahora reyes y reinas, lo aplaudieron y alabaron su valentía. Tizziano rompió el hechizo de la Kuruka que, como le contó el hada, era la reina Solaria, incapaz de comprender que los habitantes de Galia eran seres libres, con derechos para la felicidad y la convivencia.

La fiesta más increíble se organizó en nombre de Tizziano y para la felicidad de los moradores. El niño recibió una burbuja de chocolate, que examinó 
muy bien antes de abrirla y al hacerlo descubrió un ringlete de colores. Lo miró sin saber qué era, pues en su reino no existían. Al tocarlo se dio cuenta de que giraba, lo sopló fuerte y un remolino multicolor lo devolvió al otro lado del espejo, al reino de Bella las Once, sin permitirle que se despidiera de Galia.

Aún no sabía qué hacer cuando escuchó la voz de su mamá que lo llamaba: Tizziano. En sus manos tenía el ringlete, lo sopló, giró, no pasó nada extraordinario. El nuevo llamado de su mamá le recordó que debía dar un discurso, que los niños del grupo ecológico lo esperaban en el parque. Mientras bajaba pensaba que en sus manos tenía la manera de evitar que los moradores de Bella las Once mataran más mariposas de alas doradas para decorar los faroles y puertas, calles y parques durante el festival de la primavera. Ya no se extinguirían las mariposas.

También entendió por qué el hada lo envió a Galia y el poder del polvo de las alas de las mariposas. Tizziano podía decir que sus amadas mariposas estaban a salvo en el reino de Bella las Once.

\section{El hada de las flores}

\section{Isabella Pardo Pérez}

En un pueblo muy alejado de la ciudad había un orfanato donde llegaban los niños cuyos padres habían dejado abandonados. Allí llegó Daniela, una niña muy bonita y de muy buenos sentimientos. Ella tenía nueve años y sus padres en una ocasión que salieron de viaje desaparecieron, y Daniela quedó sola. Por ello llegó Daniela al orfanato. Allí se la pasaba muy triste por la soledad en que estaba, pero también a la expectativa de cómo iba a ser su nueva vida, sin saber que la directora del orfanato era una mujer muy cruel que maltrataba a los niños y en su ambición por quedarse con el dinero del orfanato les daba muy mala comida, muy mal estudio y no les entregaba los regalos que les enviaban a los niños.

Daniela, al darse cuenta de esta situación y como no tenía con quién más hablar, se la pasaba en el jardín hablándoles a las flores, pensando que ellas la escuchaban. Les contaba todas sus tristezas. Cierto día, llorando, les pidió a las flores que le ayudaran a encontrar a sus padres y que terminaran con las injusticias que se cometían en el orfanato y una lágrima cayó en ese momento en una flor y le dio vida al hada de las flores. Ella salió y empezó a hablarle a Daniela, le ofreció su ayuda, puesto que poseía el don de comunicarse con otras plantas y con los animales. Así Daniela supo que sus padres estaban en un bosque, secuestrados. El hada le indicó la ubicación, porque las aves le dijeron.

Daniela, al saber esto, se puso muy feliz y fue a contarle a la enfermera del orfanato. Ella se llamaba Diana y era muy buena, pero tenía miedo a la directora, por eso nunca dijo nada. Diana fue con un amigo suyo, que era Patricio, y le dio las indicaciones de dónde se encontraban los padres de Daniela y al otro día fueron a rescatarlos. Daniela estaba muy feliz y llorando, esta vez de alegría, agradeció al hada por su ayuda. El hada también le dijo dónde enterraba la directora el dinero que robaba y Daniela le comentó a Diana para que la denunciara, ya que tenía las pruebas.

Diana denunció a la directora del orfanato y desde ese día todo cambió para sus niños. Fueron felices y se les dio el amor y el buen trato que merecían. Como los padres de Daniela eran personas con mucho dinero le dieron mucha ayuda a Diana para el orfanato y desde ese momento fueron felices.

\section{Un mundo extraño}

\section{Daniel Sánchez Duque}

Había una vez un Niño de Acero, al que no le podían pegar. Cuando creció se volvió superhéroe. Un día se fue a salvar a un señor que se llamaba Chocolate y que era de chocolate. Cuando llegó, un rayo de chicle le quitó sus poderes, por lo que le tocó irse caminando. Unas horas más tarde llegó a una casa de helado con ventanas de paquetes de dulces y allí encontró a la Paleta Picante molestando al señor Chocolate, la cual, al verse descubierta, salió corriendo. El Niño de Acero se llevó de inmediato al señor Chocolate para el hospital porque estaba muy débil. 
Por el camino encontraron a la Paleta Picante tomando un autobús, por lo que corrieron, pero no se alcanzaron a subir. Cuando llegó el siguiente autobús le explicaron la situación al conductor y él les colaboró alcanzando al primer autobús. Cuando la Paleta Picante se dio cuenta, se bajó del autobús y corrió hacia la cerca de gomas pegajosas. El Niño de Acero y el señor Chocolate la siguieron por varias horas.

De un momento a otro apareció la Paleta Picante con sus amigos malhechores: 1) el Cono Tachuela, 2) la Paleta Grasosa y 3) el Barquillo de Aguacate con Maní. Verdocinoticias, que tenía unos verdiceptores, los estaba siguiendo y de un momento a otro interrumpieron la programación para transmitir cómo los helados acorralaban al Niño de Acero y al señor Chocolate. Llegó la policía de hielo, pero los rayos de chicle de los helados eran más fuertes. De un momento a otro, apareció un perro gigante que fue y se comió los tres helados y orinó a la Paleta Picante creyendo que era una planta.

Así se salvaron el Niño de Acero y el señor Chocolate, cuando apareció una voz en el cielo que decía: — ¡Despierta, despierta!

Resultó, al final, que todo era un sueño.

La escritura permite, como quizás puede notarse a partir de esta pequeña muestra de cuentos de niños de ocho años, laureadas por sus mismos compañeros (y, por supuesto, también de las historias que no han alcanzado aún tal reconocimiento), que estos ganen confianza en sí mismos, en sus posibilidades creativas y expresivas; que algunos descubran o desarrollen habilidades que no conocían o que no tenían y que otros más optimicen y desplieguen sus destrezas.

Si bien nuestro objetivo -tanto en este texto como en la investigación que le da origen- no es realizar un análisis de los relatos producidos por los niños, nos resulta inevitable hacer mención a algunos de los asuntos que pudieron articular su proceso creativo en torno al tema que desde el comienzo les propusimos, esto es, el niño como sujeto de derechos.

En general, los textos recogen realidades que no son desconocidas por los niños: algunas de ellas aparecen en las noticias (por ejemplo, la realidad del secuestro, la violencia contra los niños); otras remiten a diversos temas abordados en la escuela relacionados con los derechos de los niños (amor y cuidado, que contrastan con maltrato, violencia y descuido, por ejemplo); y todos, apelando a diversos recursos de una imaginación narrativa en formación, se soportan en la esperanza de superar las situaciones que sus autores, pero también los personajes de sus historias, consideran injustas.

De manera particular, el relato de Juan Esteban -que, como hemos dicho, parte de una situación de secuestro, aún presente en Latinoamérica- parece tener como telón de fondo el reclamo que en ocasiones le hacemos a los demás, cuando no consideran nuestros sentimientos y nos tratan con indiferencia ("todos lo miraban mal"), eso que solemos resumir en la sentencia: “¡acaso crees que soy de palo?”. Ante la indiferencia, el conjuro de una respuesta atenta al llamado del otro, que se expresa así: "yo te entiendo". María Juliana construye una historia en la que la narradora se pone en situación de testigo ("conocí") tanto de la actitud de Rudo como de la de Antón, del cambio del primero por la influencia del segundo, lo que contrasta con la situación del lector que se entera de todo gracias a la luminosidad del relato. Asimismo, remarca la importancia del derecho a segundas oportunidades mediadas por alguna situación particular: en el texto, propiciada por el don de Antón de "congelar los sentimientos equivocados"; en otros escenarios -el aula, la escuela, el grupo de amigos, la casa-, gracias al don de la palabra, de la creatividad para sacar a la luz el libro escondido del respeto por el otro mediante el cual los niños no son condenados cuando quieren hacer oír su propia voz. César Andrés recurre en su narración a la figura de un forastero radical, un ángel que cuestiona la naturalización de una forma de vida injusta - "nadie escucha", los niños son "un estorbo", "no hay tiempo", que un niño le hable a un adulto es una "osadía", la crianza es una "incómoda labor"-; y que, desde la simplicidad y la fuerza de su voz, hace posible el arrepentimiento, el perdón y la reconciliación. Juan Pablo arroja luces para la comprensión del dolor que subyace a todas las formas del 
mal, del sometimiento a los otros, a veces en la forma sutil de la homogeneización -"Un diferente, un extraño, que lo castiguen" - o del olvido -la cueva de la Kuruka-; y reivindica el respeto a la diferencia, al tiempo que insiste en que responsabilidad y alegría pueden emparentarse. Isabella escribe un relato en el que la voluntad de enfrentarse al miedo, articulada con la respuesta comprometida de alguien capaz de escuchar, hace posible el triunfo de la justicia sobre la maldad y la opresión; y, finalmente Daniel, que arma una historia en la que hay héroes, inocentes, acosadores, policías, periodistas, un perro gigante y dos finales -en el primero los malos reciben accidentalmente su merecido y en el segundo, que contiene al primero, irrumpe la fuerza de la verosimilitud que permite entender la composición de las cosas de ese "mundo extraño"-. De este último relato no está de más decir que cuando preguntamos a Daniel por los elementos fantásticos de su historia contestó con enorme convicción: "bueno, es que nadie le dice a uno lo que debe soñar" y, podemos agregar, en su misma línea de pensamiento: ni lo que debe o puede imaginar. Y este es uno de nuestros más valiosos hallazgos en este trabajo de investigación-acción con alumnos y maestras de escuela primaria acerca del niño como sujeto de derechos, este es nuestro propio unicornio en esta historia. Esperamos que, si el lector encuentra el suyo, lo ate con una soga encantada y lo contemple de cerca, aunque pronto tenga que liberarlo por la magia de la palabra.

\section{Referencias bibliográficas}

Mújica, M. (1979) El unicornio. Buenos Aires: Sudamericana.

Rodari, G. (1998) Gramática de la fantasía. Introducción al arte de contar historias. Bogotá: Panamericana.

Ovidio (2008). Metamorfosis. Libros I-V. Madrid: Gredos. 